\section{ASSOCIATION OF TUMOR MUTATION BURDEN (TMB) AND GENOMIC ALTERATIONS (GA) WITH CLINICAL OUTCOMES IN CHINESE PATIENTS WITH ADVANCED SOLID TUMORS TREATED WITH TISLELIZUMAB}

${ }^{1}$ Lin Shen*, ${ }^{2}$ Qingyuan Zhang, ${ }^{3}$ Tianshu Liu, ${ }^{4}$ Hongming Pan, ${ }^{2}$ Yuxian Bai, ${ }^{5}$ Ying Yuan, ${ }^{6}$ Xuerui Luo, ${ }^{7}$ Yang Shi, ${ }^{7}$ Yun Zhang, ${ }^{6}$ Ruiqi Huang, ${ }^{7}$ Juan Zhang, ${ }^{7}$ Zhirong Shen. ${ }^{1}$ Peking University Cancer Hospital and Institute, Beijing, China; ${ }^{2}$ Harbin Medical University Cancer Hospital, Harbin, China; ${ }^{3}$ Zhongshan Hospital Fudan University, Shanghai, China; ${ }^{4}$ Sir Run Run Shaw Hospital, Zhejiang University, School of Medicine, Hangzhou, China; ${ }^{5}$ The Second Affiliated Hospital of Zhejiang University School of Medicine, Hangzhou, China; ${ }^{6}$ BeiGene (Shanghai) Co., Ltd., Shanghai, China; ${ }^{7}$ BeiGene (Beijing) Co., Ltd., Beijing, China

Background Studies have demonstrated correlation of GA and TMB with clinical efficacy of an anti-programmed cell death protein-1 (PD-1) therapy, but this correlation has not yet been demonstrated in Chinese patients treated with tislelizumab (anti-PD-1 antibody). We report the association between TMB, $\mathrm{GA}$, and the clinical efficacy of tislelizumab in Chinese patients with different tumor types from a Phase $1 / 2$ study (NCT04068519).

Methods Chinese patients with advanced solid tumors who received tislelizumab monotherapy and had available tissues for genomic testing (BurningRock OncoScreen Plus 520 NGS panel) were eligible. Patients were classified as having hyperamplification (HA) if their genome harbored $\geq 1$ amplified gene with a copy number $>5$. Logistic regression was used to analyze the association of TMB with objective response rate (ORR) and Cox proportional hazard was used to determine the association of TMB with progression-free survival (PFS) and overall survival (OS).

Results A total of 156 patients were evaluable. TMB was higher in responders (R) versus non-responders (NR) (median [m] TMB: 9.3 vs 6.2 mut/Mb, $\mathrm{p}=0.003)$. TMB-H was defined as $\geq 8 \mathrm{mut} / \mathrm{Mb}$ according to the receiver operating characteristic curve. Patients in the TMB-H group showed superior clinical benefit compared with the TMB-L group (table 1). Further GA analysis showed a trend toward a higher frequency of HA in NR $(40.00 \% ; 16 / 40)$ compared with $\mathrm{R}(28.78 \% ; 5 / 18)$, in the TMB-H group. A total of $33.33 \%(10 / 30)$ of these amplified genes in NR belonged to the RTK-RAS-PI3K signaling pathway. When TMB-H patients with HA in this pathway were excluded, ORR reached $37.78 \%$.

\section{Abstract 372 Table 1 Median study follow-up and clinical} efficacy data

\begin{tabular}{|c|c|c|c|}
\hline & $\begin{array}{l}\text { Overall } \\
(\mathrm{N}=156)\end{array}$ & $\begin{array}{l}\text { TMB-H } \\
(\mathrm{n}=58)\end{array}$ & $\begin{array}{l}\text { TMB-L } \\
(\mathrm{n}=98)\end{array}$ \\
\hline $\begin{array}{l}\text { ORR, \% } \\
(95 \% \mathrm{Cl})\end{array}$ & $\begin{array}{c}16.03 \\
(10.65-22.74)\end{array}$ & $\begin{array}{c}31.03 \\
(19.54-44.54)\end{array}$ & $\begin{array}{c}7.14 \\
(2.92-14.17) \\
\end{array}$ \\
\hline $\begin{array}{l}\text { ORR odds ratio } \\
(95 \% \mathrm{Cl})\end{array}$ & - & \multicolumn{2}{|c|}{$\begin{array}{c}5.85 \\
(2.27-15.11)\end{array}$} \\
\hline $\begin{array}{l}\text { Median PFS, mo } \\
(95 \% \mathrm{CI})\end{array}$ & $\begin{array}{c}2.30 \\
(2.17-2.92)\end{array}$ & $\begin{array}{c}6.11 \\
(2.20-10.45)\end{array}$ & $\begin{array}{c}2.20 \\
(2.10-2.30)\end{array}$ \\
\hline $\begin{array}{l}\text { PFS hazard ratio } \\
(95 \% \mathrm{Cl})\end{array}$ & - & \multicolumn{2}{|c|}{$\begin{array}{c}0.54 \\
(0.38-0.78)\end{array}$} \\
\hline $\begin{array}{l}\text { Median OS, mo } \\
(95 \% \mathrm{Cl})\end{array}$ & $\begin{array}{c}12.48 \\
(8.51-17.58)\end{array}$ & $\begin{array}{c}21.74 \\
(12.88-\mathrm{NE})\end{array}$ & $\begin{array}{c}8.94 \\
(5.88-13.44)\end{array}$ \\
\hline $\begin{array}{l}\text { OS hazard ratio } \\
(95 \% \mathrm{Cl})\end{array}$ & - & \multicolumn{2}{|c|}{$\begin{array}{ccc}(12.00-\text { IVL }) & 0.55 \\
(0.36-0.83) & (0.00-10.44) \\
& \end{array}$} \\
\hline $\begin{array}{l}\text { Median follow-up, mo } \\
(95 \% \mathrm{Cl})\end{array}$ & $\begin{array}{c}28.55 \\
(26.68-32.46)\end{array}$ & $\begin{array}{c}29.37 \\
(26.78-33.05)\end{array}$ & $\begin{array}{c}27.56 \\
(24.48-32.46)\end{array}$ \\
\hline
\end{tabular}

$\mathrm{NE}$, non-estimable

Conclusions TMB-H status was associated with improved clinical efficacy of tislelizumab in Chinese patients with advanced solid tumors, consistent with other PD-1 inhibitors. These observations support TMB-H as a potential predictive biomarker for response to tislelizumab in this patient population. $\mathrm{HA}$ in the RTK-RAS-PI3K pathway may be associated with resistance mechanisms to anti-PD-1 therapy, even in patients with TMB-H tumors.

Acknowledgements Editorial writing support for the development of this abstract, under direction of the authors, was provided by Louise Oakes, $\mathrm{PhD}$, of Ashfield MedComms, an Ashfield Health company, and was funded by BeiGene Ltd. Trial Registration NCT04068519

Ethics Approval This study was conducted according to the ethical principles of the Declaration of Helsinki, Good Clinical Practice guidelines, the principles of informed consent and the requirements of the public registration of clinical trials. Written informed consent was obtained from each patient prior to screening. The protocol was approved by the institutional ethics committee and was monitored by the investigators and study sponsor.

http://dx.doi.org/10.1136/jitc-2021-SITC2021.372 